\title{
Caracterização preliminar de amostras do vírus da Diarréia Viral Bovina (BVDV) isoladas no Brasil ${ }^{1}$
}

\author{
Sônia A. Botton², Laura Helena V.G. Gil ${ }^{2}$, Adriana M. da Silva² ${ }^{2}$ Eduardo F. Flores ${ }^{3,4}$, \\ Rudi Weiblen ${ }^{3}$, E. Maristela Pituco ${ }^{5}$, Paulo M. Roehe ${ }^{6}$, Valéria Moojen ${ }^{7}$ e Ana \\ Cristina Wendelstein ${ }^{7}$
}

\begin{abstract}
Botton S.A., Gil L.H.V.G., Silva A.M., Flores E.F., Weiblen R., Pituco E.M., Roehe P.M., Moojen V. \& Wendelstein, A.C. 1998. [Preliminary characterization of brazilian isolates of bovine viral diarrhea virus (BVDV). [ Caracterização preliminar de amostras do vírus da Diarréia Viral Bovina (BVDV) isoladas no Brasil. Pesquisa Veterinária Brasileira, 18(2)83-90. Depto Medicina Veterinária Preventiva, Microbiologia e Parasitologia, Universidade Federal de Santa Maria, Santa Maria, RS 97015-900, Brazil.

This article reports the preliminary characterization of 19 Brazilian bovine viral diarrhea virus (BVDV) isolates, regarding the biological, antigenic and molecular properties. Eleven viruses were isolated from bovine fetuses, six were obtained from blood of animals from herds with reproductive problems, and two were isolated from clinical cases of gastroenteric disease. The clinical cases affected young animals and were characterized by diarrhea, oronasal and digestive erosions and ulceration, and occasional digestive bleeding and vulvar petechial hemorrhage. Sixteen isolates (84.2\%), including those obtained from fetuses and clinical cases, were of the non-cytopathic (ncp) biotype. Replication of three isolates (15.8\%) in tissue culture was characterized by appearance of cellular vacuolation and progressive destruction of the monolayers. Analysis of these isolates after cloning revealed a mixed population of cytopathic (cp) and non-cytopathic viruses. Analysis of viral polypeptides by SDS-PAGE followed by "Western immunoblot" revealed the production of the nonstructural protein NS3/p80 in cells infected with the cp viruses. In contrast, generation of NS3/p80 was not observed in cells infected with the ncp isolates, which only expressed the precursor polypeptide NS23/p125. Analysis of reactivity with a panel of 15 monoclonal antibodies (MAbs) revealed a marked antigenic variability among the isolates, mainly in the envelope glycoprotein E2/ gp53. Although one MAb to this glycoprotein recognized 18 isolates (94.7\%), the other nine E2/ gp53 MAbs recognized zero to $57.9 \%$ of the isolates. The marked antigenic diversity observed among the brazilian BVDV isolates may have important implications on diagnosis and immunization strategies.
\end{abstract}

INDEX TERMS: Bovine viral diarrhea virus, BVDV, biotypes, antigenic diversity.

\footnotetext{
${ }^{1}$ Aceito para publicação em 18 de março de 1998.

Parte da tese de Mestrado dos dois primeiros autores. Programa de PósGraduação em Medicina Veterinária, Universidade Federal de Santa Maria (UFSM).

${ }^{2}$ Mestrando em Medicina Veterinária, UFSM.

${ }^{3}$ Departamento de Medicina Veterinária Preventiva (DMVP), Microbiologia e Parasitologia (DMP), UFSM.

${ }^{4}$ Autor para correspondência:DMVP/UFSM, Santa Maria, RS 97015-900. Fax:(055)220-8257. E-mail: Flores@ccr.ufsm.br. Bolsista do CNPq (352386/ 96-7).

${ }^{5}$ Instituto Biológico de São Paulo, São Paulo, SP

${ }^{6}$ Centro de Pesquisas Veterinárias Desidério Finamor (CPVDF), Eldorado do Sul, RS, e Departamento de Microbiologia, Universidade Federal do Rio Grande do Sul, Porto Alegre, RS.

${ }^{7}$ Faculdade de Veterinária, Universidade Federal do Rio Grande do Sul (UFRGS), Porto Alegre, RS.
}

RESUMO.- 0 presente artigo relata a caracterização inicial de 19 amostras do vírus da Diarréia Viral Bovina (BVDV) isoladas no Brasil, com relação a aspectos biológicos, antigênicos e moleculares. Onze amostras foram isoladas de fetos bovinos, seis foram obtidas do sangue de animais clinicamente saudáveis de rebanhos com problemas reprodutivos e duas amostras foram isoladas de casos clínicos de enfermidade gastrentérica. Os casos de doença entérica afetaram animais jovens e cursaram com diarréia, às vezes sanguinolenta, erosões e ulcerações na mucosa oronasal e do trato digestivo, e eventualmente hemorragias digestivas e petéquias na vulva. Dezesseis amostras (84,2\%), incluindo aquelas isoladas de fetos e dos casos clínicos, pertencem ao biotipo não-citopático (ncp). A replicação de outras três amostras (15,8\%), foi caracterizada pelo aparecimento de vacuolização e destruição progressiva do tapete celular. A análi- 
se das amostras que produziram citopatologia, após clonagem, revelou tratar-se de populações mistas composta de vírus citopáticos (cp) e não-citopáticos. A análise de polipeptídeos virais através de SDS-PAGE seguida de "Western-immunoblot" revelou a produção da proteína não-estrutural NS3/p80 em células infectadas com as amostras cp. Em contraste, não se evidenciou a geração da NS3/p80 em células infectadas com as amostras ncp que produziram apenas o polipeptídeo precursor NS23/ p125. A subsequente análise de reatividade frente a um painel de 15 anticorpos monoclonais (AcMs) revelou uma diversidade antigênica marcante entre os isolados, sobretudo na glicoproteína E2/gp53. Embora um AcM contra essa glicoproteína reagiu com 18 isolados (94,7\%), outros nove AcMs anti-E2/gp53 reconheceram entre zero e $57,9 \%$ das amostras brasileiras. A grande variabilidade antigênica detectada entre as amostras brasileiras do BVDV pode ter importantes implicações para o diagnóstico e estratégias de controle e imunização contra 0 vírus.

TERMOS DE INDEXAÇÃO: Vírus da Diarréia Viral Bovina, BVDV, biotipos, diversidade antigênica.

\section{INTRODUÇÃO}

O vírus da Diarréia Viral Bovina (bovine viral diarrhea virus - BVDV) é um dos principais patógenos de bovinos e causa perdas significativas à bovinocultura de corte e leite em todo o mundo (Bolin 1990). O BVDV é um vírus RNA de polaridade positiva, com envelope, pertencente à família Flaviviridae, gênero Pestivirus. Este gênero inclui também o vírus da Peste Suína Clássica (Classical swine fever virus - CSFV) e o vírus da Doença da Fronteira (Border disease virus - BDV) de ovinos (Francki et al. 1991) .

A infecção de bovinos pelo BVDV tem sido associada a diversas manifestações, que variam desde infecções subclínicas até a altamente fatal Doença das Mucosas (Brownlie 1990, Baker 1995). Síndromes gastrentéricas, respiratórias ou hemorrágicas, mortalidade embrionária, abortos ou mumificação fetal, malformações fetais e nascimento de bezerros inviáveis estão entre as consequências da infecção pelo BVDV (Brownlie 1990, Baker 1995). A infecção de fêmeas prenhes entre os dias $40 \mathrm{e}$ 120 de gestação frequentemente resulta em infecção fetal com o subsequente nascimento de bezerros imunotolerantes, persistentemente infectados (PI) (Brownlie 1990, Moennig \& Liess 1995). Esses animais desempenham um papel central na epidemiologia da infecção, pois não são facilmente identificáveis e representam fontes contínuas de disseminação do vírus (Donis 1989, Brownlie 1990, Houe 1995).

Dois biotipos do BVDV podem ser reconhecidos com base no efeito da sua replicação em células de cultivo: cepas nãocitopáticas (ncp) e cepas citopáticas (cp) (Lee \& Gillespie 1957, Gillespie et al. 1960, Liess 1996). As cepas ncp representam a maioria dos isolados de campo, e estão associadas às diversas manifestações clínicas da infecção (Lee \& Gillespie 1957, Liess 1996). Cepas citopáticas são isoladas quase que exclusivamente de casos da Doença das Mucosas e parecem originar-se de cepas não-citopáticas através de mutações e/ou recombinações no genoma (Mc Clurkin et al. 1985, Meyers et al. 1991, 1992, 1996). A indução de citopatologia em células de cultivo tem sido correlacionada com a habilidade do vírus em expressar a proteína não-estrutural NS3/p80 a partir do polipeptídeo precursor NS23/p125 (Donis \& Dubovi 1987, Meyers et al. 1996).

Amostras de campo do BVDV apresentam uma diversidade antigênica considerável, embora ainda não tenha sido possível uma definição clara de sorotipos (Dubovi 1992). As regiões de maior variabilidade encontram-se nas glicoproteínas do envelope, principalmente na E2/gp53 (Donis et al. 1988, Corapi et al. 1990, Dubovi 1992, Edwards \& Paton 1995). A grande variabilidade antigênica observada entre isolados do BVDV possui significado especial para a epidemiologia, diagnóstico e para estratégias de imunização e controle da enfermidade causada pelo vírus (Edwards \& Paton 1995).

O presente artigo relata a caracterização inicial de 19 amostras de BVDV isoladas de bovinos em vários estados do Brasil. Amostras isoladas de casos clínicos, de fetos e de animais PI foram caracterizadas quanto ao seu biotipo, reatividade com anticorpos monoclonais (AcMs), e clivagem da NS23/p125 e geração da NS3/p80.

\section{MATERIAL E MÉTODOS}

Células e vírus

A origem das amostras do BVDV caracterizadas nesse estudo está relacionada no Quadro 1. Treze amostras foram isoladas no Laboratório de Virologia da Universidade Federal de Santa Maria (UFSM). As demais amostras foram isoladas de casos clínicos e do sangue de animais clinicamente sadios, nos laboratórios relacionados (Quadro 1). As amostras foram multiplicadas em células de linhagem de rim fetal bovino (MDBK), livres de Pestivirus. As células MDBK foram rotineiramente mantidas em meio essencial mínimo (MEM), com penicilina $(35 \mathrm{mg} / \mathrm{l})$, estreptomicina $(200 \mathrm{mg} / \mathrm{l})$, suplementado com $5 \%$ de soro fetal equino (Gibco, BRL, USA).

\section{Reatividade com anticorpos monoclonais}

Para a caracterização antigênica das amostras, utilizaram-se 15 anticorpos monoclonais (AcMs) específicos para a cepa padrão Singer, produzidos e caracterizados por Corapi et al. (1990). A especificidade de cada AcM utilizado nessa caracterização está indicada no Quadro 2. A habilidade de cada AcM de reconhecer e ligar-se aos antígenos virais foi examinada através do teste de imunofluorescência indireta (IFI). Lâminas contendo células infectadas com cada um dos isolados foram inicialmente fixadas em acetona (previamente resfriada a $0^{\circ}$ C) durante $5 \mathrm{~min}$. Após, foram incubadas por $1 \mathrm{~h}$ a $37^{\circ} \mathrm{C}$ com cada AcM (fluido ascítico diluído 1:500 em PBS ou sobrenadante de cultivo de hibridomas), seguido de lavagem em água destilada e nova incubação $\left(1 \mathrm{~h} \mathrm{a} 37^{\circ} \mathrm{C}\right)$ com o anticorpo secundário (anticorpo policlonal de cabra, anti-IgG de camundongo, conjugado com isotiocianato de fluoresceína, Sigma, USA). A seguir, as lâminas foram lavadas, coradas com azul de Evans (0.01\%) por $1 \mathrm{~min}$, montadas com glicerol:PBS (1:1) e lamínula e observadas em microscópio de epifluorescência. Células não infectadas, células infectadas com a cepa Singer e incubadas com cada AcM, além de células infectadas com cada isolado e coradas com um pool de anticorpos monoclonais, foram utilizadas como controles.

\section{Ensaios de placa e clonagem dos vírus}

Para clonagem dos vírus, tapetes confluentes de células MDBK cultivados em placas de poliestireno de 6 cavidades foram inoculados com as amostras de vírus em diferentes diluições. Após adsorção em estufa de $\mathrm{CO}_{2}$ a $37^{\circ} \mathrm{C}$ por $1 \mathrm{~h}$, o inóculo foi removido e os tapetes 
Quadro 1. Amostras do vírus da Diarréia Viral Bovina (BVDV) caracterizadas no presente estudo

\begin{tabular}{|c|c|c|c|c|c|}
\hline Identificação & Biotipo & Animal/caso clínico & Espécimen & Local & Ano \\
\hline UFSM-1 ${ }^{\mathrm{a}}$ & $n c p^{b}$ & Feto & Soro & Farroupilha, RS & 1996 \\
\hline UFSM-2 & ncp & Feto & Soro & Alegrete,RS & 1996 \\
\hline UFSM-3 & ncp & Bezerro macho saudável & Soro & Pelotas, RS & 1997 \\
\hline SV-123.4 & ncp & Feto & Soro & Santa Maria, RS & 1996 \\
\hline SV-126.1 & ncp & Feto & Soro & Santa Maria, RS & 1996 \\
\hline SV-126.8 & ncp & Feto & Soro & Farroupilha, RS & 1996 \\
\hline SV-126.14 & ncp & Feto & Soro & Santa Maria, RS & 1996 \\
\hline SV-152 & ncp & Feto & Soro & Farroupilha, RS & 1996 \\
\hline SV-153.1 & ncp & Feto & Soro & Lavras do Sul, RS & 1996 \\
\hline SV-153.15 & ncp & Feto & Soro & Lavras do Sul, RS & 1996 \\
\hline SV-153.19 & ncp & Feto & Soro & S. F. de Assis, RS & 1996 \\
\hline SV-63 & ncp & Feto & Soro & Santa Maria, RS & 1996 \\
\hline SV-260 & ncp & $\begin{array}{l}\text { Bezerra de } 9 \text { meses de idade, com enterite, erosões } \\
\text { e ulcerações na cavidade oral, esôfago e intestino }\end{array}$ & Baço & Lages, SC & 1997 \\
\hline LV85/96 & ncp & $\begin{array}{l}\text { Novilha com crescimento retardado a partir dos } \\
\text { seis meses de idade, diarréia, ulcerações na língua, } \\
\text { erosões orais, nasais, no esôfago, petéquias vulvares }\end{array}$ & Leucócitos & Viamão, RS & 1996 \\
\hline EVI-006 ${ }^{d}$ & ncp & $\begin{array}{l}\text { Bezerro saudável de um rebanho com problemas } \\
\text { reprodutivos }\end{array}$ & Soro & Eldorado do Sul, RS & 1995 \\
\hline IBSP-1 $^{\mathrm{e}}$ & ncp & idem & Leucócitos & Jaboticabal, SP & 1995 \\
\hline IBSP-2 & $\mathrm{cp} / \mathrm{ncp}^{\mathrm{f}}$ & idem & Leucócitos & Jaboticabal, SP & 1995 \\
\hline IBSP-4 & $\mathrm{cp} / \mathrm{ncp}$ & idem & Leucócitos & Ribeirão Preto, SP & 1995 \\
\hline IBSP-5 & $\mathrm{cp} / \mathrm{ncp}$ & idem & leucócitos & Ribeirão Preto, SP & 1995 \\
\hline
\end{tabular}

aLaboratório de Virologia, Universidade Federal de Santa Maria, RS. 'bAmostra não citopática. 'Laboratório de Virologia, Faculdade de Veterinária, Universidade Federal do Rio Grande do Sul. dCentro de Pesquisas Veterinárias Desidério Finamor (CPVDF-RS), Eldorado do Sul, RS. ' Instituto Biológico de São Paulo, SP. ṔPopulação mista de vírus citopáticos e não citopáticos.

celulares recobertos com um gel de agarose ( $1 \%$ de agarose em meio completo de cultivo) aquecido a $39^{\circ} \mathrm{C}$. Após solidificação do gel, as placas foram incubadas em estufa de $\mathrm{CO}_{2}$ a $37^{\circ} \mathrm{C}$ por 72 a $96 \mathrm{~h}$, quando removeu-se a cobertura de ágar. Para a obtenção de vírus citopáticos, as placas individuais foram coletadas com o auxílio de ponteiras plásticas e posteriormente amplificadas em células MDBK. Após a coleta, para melhor visualização das placas, os tapetes celulares foram corados com solução de cristal violeta $(0,013 \%$ cristal violeta + $5 \%$ formalina durante $2 \mathrm{~min}$ ) ou pela técnica de imunoperoxidase. A clonagem dos vírus não citopáticos foi realizada através do método de diluição limitante (Mayr \& Guerreiro 1981).

\section{Ensaios de placa e clonagem dos vírus}

Para a técnica de imunoperoxidase, as células aderidas às lâminas de microscopia ou placas de cultivo foram fixadas em $35 \%$ acetona em PBS por $10 \mathrm{~min}$. Posteriormente, foram lavadas com PBS, secas ao ar e incubadas com um pool de AcMs (diluídos 1:5 em PBS) por $1 \mathrm{~h}$ a $37^{\circ} \mathrm{C}$. Após lavagem ( $3 \mathrm{X}$ em PBS $+0,05 \%$ Tween 20$)$, as células foram incubadas com o anticorpo secundário (anticorpo de cabra anti IgG de camundongo, conjugado com peroxidase, Sigma, USA) pelo mesmo período. Após nova lavagem, as células foram incubadas com o substrato (9-amino-2-ethyl-carbazole (AEC) 0,05\%, em solução 0,05 M acetato de sódio pH 5,0 + água oxigenada 1:1000). Realizou-se a leitura 15 a 30 min após, em microscópio óptico invertido.

Análise de proteínas virais

Análise das proteínas não estruturais NS23/p125 e NS3/p80 foi realizada através da técnica de "Western immunoblot", acoplada ao método de luminescência química (chemiluminescence, ECL) (Amersham, Inc., USA). Células MDBK infectadas com cada amostra de vírus foram lisadas em tampão de lise (Laemnli 1970) e as prote- ínas celulares foram separadas por eletroforese em gel de poliacrilamida a $8,5 \%$ (Ausubel et al. 1989). Após, as proteínas foram transferidas para membranas de nitrocelulose (Biorad, USA), utilizando-se o sistema de transferência semi-seco por $2 \mathrm{~h}$, segundo instruções do fabricante (Biorad). Após a transferência, as membranas foram inicialmente incubadas, em agitação, com a solução bloqueadora PBS-TL (PBS + 0,05\% Tween $20+3 \%$ leite em pó desnatado) por $1 \mathrm{~h}$ a temperatura ambiente $(\mathrm{TA})\left(21-25^{\circ} \mathrm{C}\right)$. A seguir, as membranas foram incubadas com o anticorpo monoclonal 20.10.6 (Corapi et al. 1990), diluído 1:10000 em PBS-TL por 1h a TA, seguido de 3 lavagens com PBS-Tween 20 (5 min cada). As membranas foram então incubadas com o anticorpo secundário (anticorpo de cabra, anti IgG de camundongo, conjugado com peroxidase, Sigma, USA) diluído 1:1000 em PBS-TL, por 1h a TA. Após novas lavagens, as membranas foram incubadas com o substrato "luminol" (Amersham, Inc., USA) por $1 \mathrm{~min}$. A luminescência química, resultado da atividade da peroxidase sobre o substrato, foi captada pela exposição da membrana a filmes de raios X (Kodak).

\section{RESULTADOS}

Amostras do BVDV isoladas no Brasil

As amostras caracterizadas neste estudo representam a maioria das amostras de campo do BVDV disponíveis no Brasil. Amostras isoladas de soro bovino comercial ou de linhagens celulares não foram incluídas. A identificação, o biotipo, a origem, o espécimen/órgão a partir dos quais as amostras foram isoladas e o local de isolamento estão listados no Quadro 1.

Dezesseis das amostras isoladas $(84,2 \%)$ pertencem ao biotipo ncp, incluindo as amostras isoladas de fetos e de casos clínicos (Quadro 1). A replicação desses vírus em células de cultivo não 


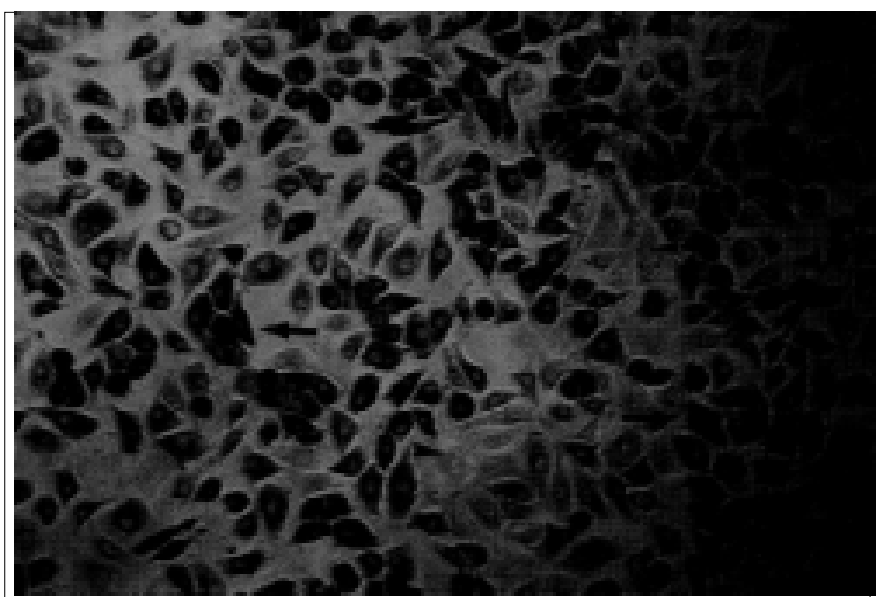

Fig. 1. Células MDBK infectadas com uma amostra de vírus BVDV não-citopático e coradas pela técnica de imunoperoxidase. Algumas células negativas para antígenos virais (cabeças de seta) podem ser observadas em meio a maioria de células positivas (setas). 250x.

produziu alterações morfológicas e nem afetou a fisiologia ou o crescimento celular. Por isso, a identificação dos vírus ncp após a inoculação e isolamento em cultivo celular foi realizada através da deteç̧ão de antígenos virais nos testes de imunofluorescência e/ou imunoperoxidase (Fig. 1). Esta característica contrasta com a replicação das cepas $\mathrm{cp}$, as quais produziram citopatologia

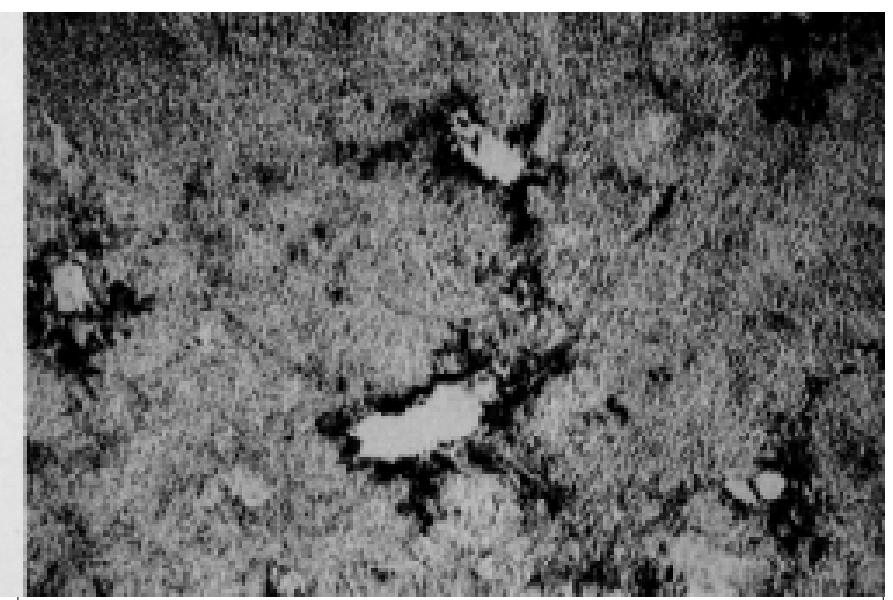

Fig. 2. Monocamadas de células MDBK infectadas com um vírus BVDV citopático clonadas a partir da amostra IBSP-2, coradas pela técnica de imunoperoxidase. Focos de lise celular circundados por células positivas para antígenos virais podem ser observados em meio a um tapete celular íntegro formado por células negativas. 160x.

severa caracterizada por vacuolização e destruição progressiva do tapete celular (Fig. 2). Duas amostras (IBSP-2 e IBSP-5) produziram citopatologia evidente desde as primeiras passagens em células MDBK, enquanto a amostra IBSP-4 somente produziu efeito citopático (ECP) após sucessivas passagens. Clonagem das amostras que produziram citopatologia revelou tratar-se de

Quadro 2. Reatividade de um painel de anticorpos monoclonais produzidos com a cepa Singer frente às amostras do vírus da Diarréia Viral Bovina (BVDV) isoladas no Brasil ${ }^{\mathrm{a}}$

\begin{tabular}{|c|c|c|c|c|c|c|c|c|c|c|c|c|c|c|c|}
\hline \multirow[t]{3}{*}{ Amostra } & \multicolumn{15}{|c|}{ Especificidade/AcM } \\
\hline & \multicolumn{4}{|c|}{$\begin{array}{l}\text { Proteína não-estrutural } \\
\text { NS3/p125 }\end{array}$} & \multicolumn{2}{|c|}{$\begin{array}{l}\text { Glicoproteína } \\
\text { E0/gp48 }\end{array}$} & \multicolumn{9}{|c|}{ Glicoproteína E2/gp53 } \\
\hline & 8.12 .7 & 20.10 .6 & 15.14 .5 & $15 c 5$ & $3 \mathrm{~d} 8$ & $12 \mathrm{~g} 4$ & $19 f 7$ & $27 \mathrm{~b} 3$ & $20 \mathrm{~g} 7$ & $6 \mathrm{~d} 11$ & $10 \mathrm{fg}$ & $18 \mathrm{~d} 4$ & $4 \mathrm{~d} 8$ & 7.1 .8 & 25 e6 \\
\hline Singer & $++^{b}$ & + & + & + & + & + & + & + & + & + & + & + & + & + & + \\
\hline UFSM-1 & + & + & + & + & $-\mathrm{c}$ & - & - & - & - & - & - & - & - & $(+)^{d}$ & - \\
\hline UFSM-2 & + & + & + & + & - & - & - & - & + & + & - & - & - & + & - \\
\hline UFSM-3 & + & + & + & + & - & + & + & - & + & - & - & + & + & + & + \\
\hline SV-123.4 & + & + & + & + & - & $(+)$ & + & - & - & $(+)$ & - & + & + & + & $(+)$ \\
\hline SV-126.1 & $(+)$ & + & + & + & + & + & + & - & + & - & + & + & + & + & + \\
\hline SV-126.8 & + & + & + & + & + & + & + & - & + & + & - & + & - & + & + \\
\hline SV-126.14 & + & + & + & + & - & - & - & - & - & - & - & - & - & - & - \\
\hline SV-152 & + & + & + & + & + & + & + & - & - & $(+)$ & - & + & - & + & - \\
\hline SV-153.1 & + & + & + & + & - & - & - & - & - & - & - & - & - & + & - \\
\hline SV-153.15 & + & + & + & + & - & - & - & - & - & - & - & - & + & + & - \\
\hline SV-153.19 & + & + & + & + & - & + & - & - & - & - & - & - & - & + & - \\
\hline SV-63 & + & + & - & + & - & - & + & - & + & - & - & - & - & + & - \\
\hline SV-260 & + & + & + & + & - & + & - & - & - & - & + & - & - & + & - \\
\hline EVI006 & + & + & $(+)$ & $(+)$ & + & - & + & - & + & + & - & + & + & + & + \\
\hline LV 85/96 & + & + & + & + & $(+)$ & - & $(+)$ & - & - & + & $(+)$ & - & - & + & - \\
\hline IBSP-1 & $(+)$ & + & + & + & - & - & - & - & - & - & - & + & - & + & - \\
\hline IBSP -2 & - & + & + & + & $(+)$ & - & + & - & $(+)$ & - & - & + & - & + & - \\
\hline IBSP -4 & + & + & + & + & + & - & + & - & - & - & - & + & - & + & - \\
\hline IBSP -5 & $(+)$ & + & + & + & $(+)$ & $(+)$ & + & - & - & - & - & + & - & + & - \\
\hline
\end{tabular}

a Reatividade no teste de imunofluorescência indireta, utilizando os AcMs individuais (fluido ascítico 1:500 ou sobrenadante de cultivo de hibridomas) como anticorpo primário e anticorpo anti-IgG de camundongo conjugado com fluorescência como anticorpo secundário. bFluorescência de intensidade forte. 'Ausência de fluorescência. 'Pluorescência fraca ou um número pequeno de células coradas. 


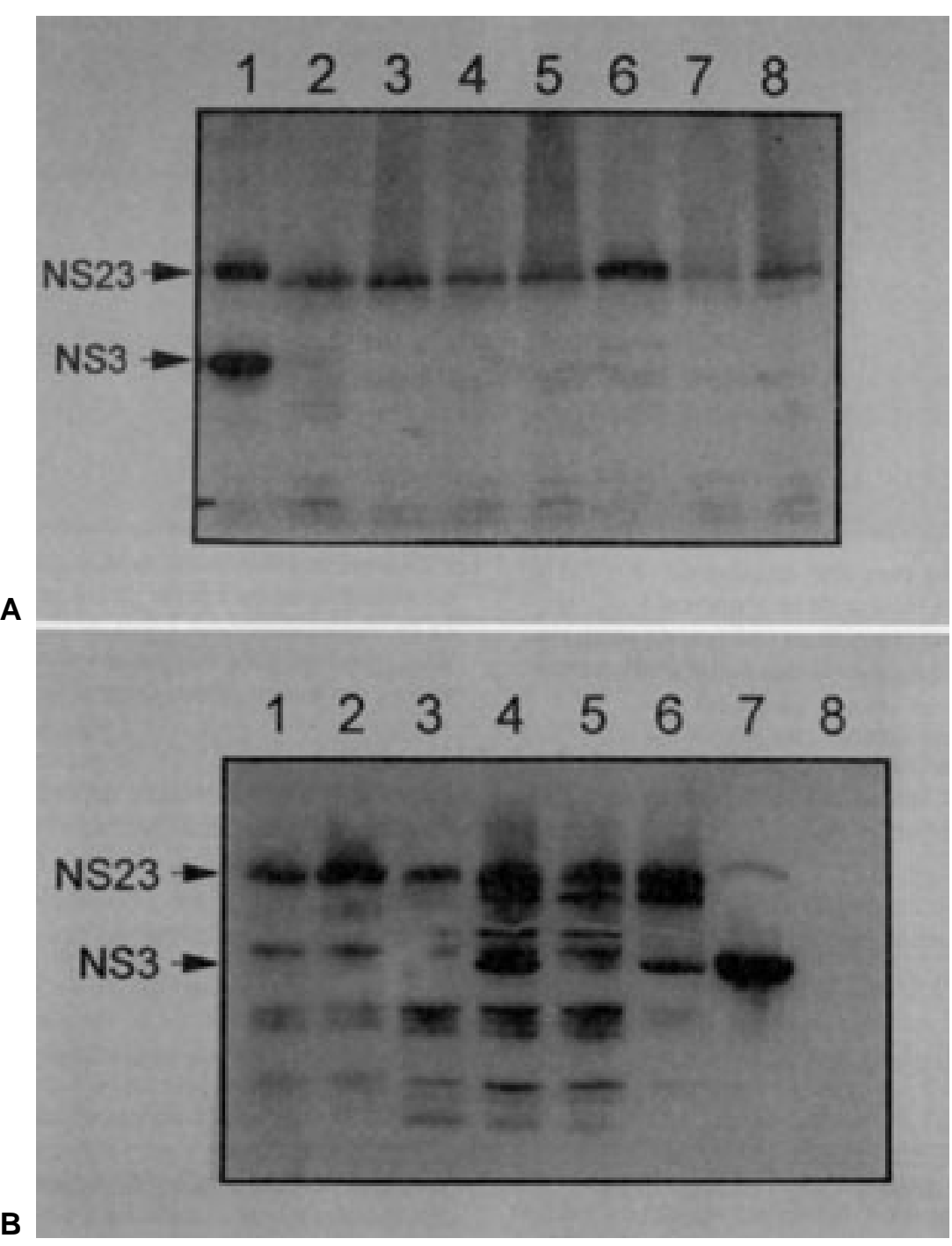

Fig. 3. "Western immunoblot" de lisados de células infectadas com a cepa padrão Singer e com amostras brasileiras do BVDV. (A) Linha 1: Singer, 2: UFSM-1, 3: UFSM-2, 4: SV-63-3, 5: SV-153.1, 6: SV-153.15, 7: SV-126.8, e 8: SV-152. (B) Linha 1: SV-260/97, 2: LV85/96, 3: EVI-006, 4: IBSP-5, 5: IBSP-4, 6: IBSP-2, 7: Singer, 8: células MDBK não-infectadas. As setas indicam as posições da proteína não-estrutural NS23/p125 e de seu produto de clivagem, proteína NS3/p80.

populações mistas de ambos os biotipos. Após a clonagem, a presença de vírus não-citopáticos foi evidenciada por imunocitoquímica e a de vírus citopáticos pela produção de focos de destruição em tapetes celulares corados com cristal violeta ou por imunocitoquímica (Fig. 2).

Análise de proteínas virais

As Figuras 3A e 3B apresentam os resultados da análise de polipeptídeos virais em células infectadas com a cepa padrão Singer e com algumas das amostras brasileiras de BVDV. As proteínas foram analisadas através da técnica de "Westernimmunoblot", utilizando-se como sonda o anticorpo monoclonal 20.10.6, que reconhece a região carboxi-terminal (NS3/p80) da proteína não-estrutural NS23-p125 (Corapi et al. 1990). Duas bandas de reatividade podem ser evidenciadas nos lisados de células infectadas com a cepa citopática Singer (Fig. 3A, linha 1;
Fig. 3B, linha 7). A maioria das amostras brasileiras não apresentou produção da proteína NS3/p80, demonstrando apenas uma banda de reatividade, correspondente a proteína precursora NS23/p125 (Fig. 3A, linhas 2-8; Fig. 3B, linhas 1-3). Apenas os lisados de células infectadas com as três amostras que produziram citopatologia (IBSP-2, 4 e 5) apresentaram duas bandas de reatividade. A banda superior corresponde a proteína NS23/ p125 e a banda inferior corresponde a proteína NS3/p80 (Fig. 3B, linhas 4, 5 e 6). A proporção de NS3/p80 em relação a NS23/ p125, no entanto, foi significativamente menor nas amostras brasileiras do que na cepa Singer. As outras bandas observadas na Figura 3B são provavelmente derivadas da reatividade do anticorpo com produtos de degradação das proteínas precursoras. Em resumo, a análise de proteínas virais através da técnica de "Western immunoblot" revelou dois padrões de expressão da proteína não estrutural NS23/p125: 1) produção somente da 
proteína precursora pelas amostras ncp e 2) produção concomitante da proteína NS3/p80 pelas amostras $\mathrm{cp}$.

Reatividade com anticorpos monoclonais

$O$ perfil de reatividade das amostras brasileiras de BVDV com 15 AcMs produzidos com a cepa padrão Singer está apresentado no Quadro 2. Os AcMs 20.10.6 (NS23/p125) e 15c5 (E0/ gp48) reagiram com a totalidade das amostras. Dois AcMs contra a proteína não-estrutural NS23/p125 (8.12.7 e 15.14.5) reconheceram 18 amostras (94.7\%). Os AcMs específicos para a glicoproteína principal do envelope do vírus (E2/gp53) apresentaram um espectro bastante variável de reatividade, reconhecendo de zero a 18 amostras. Dentre estes, o anticorpo 7.1.8 foi o que reconheceu o maior número de amostras (18 ou 94,7\%). Das amostras analisadas, 9 reagiram com menos de 50\% dos AcMs. A amostra SV-126.14 foi reconhecida pelo menor número de anticorpos ( 4 ou 26,6\%), seguida de duas amostras que foram reconhecidas por 5 anticorpos (33,3\%) (UFSM-1, SV-153.1) e de outras quatro amostras que reagiram com 6 AcMs (40\%)(SV153.15, SV-153.19, SV-63 e IBSP-1). A amostra SV-126.1 reagiu com o maior número de AcMs (13 MAbs ou 86,6\%), seguida das amostras SV-126.8 e EVI-006, que foram reconhecidas por 12 anticorpos (80\%). Dentre as 19 amostras analisadas, apenas duas (UFSM-1 e SV-153.1) apresentaram perfis idênticos de reconhecimento entre si. Portanto, as amostras estudadas do BVDV apresentavam uma variabilidade antigênica marcante quando examinadas frente aos AcMs utilizados, sendo essa variabilidade mais evidente na região da glicoproteína E2/gp53.

\section{DISCUSSÃO}

Informações referentes à infecção e enfermidades associadas ao BVDV no Brasil são escassas e não sistemáticas. Alguns relatos foram publicados nas décadas de 60 e 70, descrevendo episódios de enfermidades clinicamente semelhantes as síndromes associadas ao BVDV (Correa et al. 1968, 1972) e sorologia positiva em bovinos do Estado de São Paulo (Soares \& Carvalho Pereira 1974). O primeiro isolamento do BVDV no Brasil foi realizado por Vidor (1974), a partir do sangue de um feto aparentemente sadio, coletado em um matadouro no Rio Grande do Sul. Recentemente, dados de sorologia e isolamento de vírus de linhagens celulares e de soro de bezerros têm sido relatados (Roehe et al. 1995, Oliveira et al. 1996). Essa escassez de informações relativas ao BVDV deve-se sobretudo a grande ênfase dada a Febre Aftosa durante muitos anos e a falta de técnicos treinados e de reagentes apropriados ao diagnóstico da infecção. Nos últimos anos, alguns laboratórios iniciaram atividades sistemáticas de diagnóstico, produção de reagentes e pesquisas relacionadas ao BVDV. Isto tem contribuído para um acúmulo gradativo de informações sobre a infeç̧ão no Brasil.

Grande parte das amostras analisadas foram isoladas do soro de fetos coletados em matadouros no Estado do Rio Grande do Sul. O objetivo da coleta e análise do sangue desses fetos foi obter amostras do BVDV para serem posteriormente caracterizadas. Fetos persistentemente infectados representam uma fonte rápida e prontamente disponível para a obtenção de amostras de BVDV, já que a infecção fetal é um evento relativamente frequente na epidemiologia da infecção (Baker 1995). Embora in- formações adicionais, sobretudo referentes a epidemiologia e patogenia dessas amostras não estejam disponíveis, elas provavelmente são representativas de uma parcela das amostras de vírus que circulam nas populações bovinas de origem. De um total de 1396 amostras testadas, $11(0,78 \%)$ continham vírus e outras $19(1,36 \%)$ continham anticorpos neutralizantes anti-BVDV, totalizando $2,15 \%$ de infecções fetais na população estudada (Dados não publicados). A presença de vírus no sangue desses fetos é sugestiva de que a infecção fetal ocorreu entre os dias 40 e 120 de gestação (Baker 1995, Moennig \& Liess 1995). Infecções nesse período, quando não resultam em mortalidade fetal, geralmente são seguidas do estabelecimento de persistência viral com indução de imunotolerância (Baker 1995). Esses fetos, se levados a termo, geralmente originam bezerros PI, que constituem as principais fontes de disseminação do vírus (Donis 1989, Brownlie 1990, Houe 1995). Animais PI são muitas vezes clinicamente saudios e por isso de difícil reconhecimento (Baker 1995, Houe 1995). Por isso, mesmo um índice aparentemente baixo de fetos infectados pode constituir-se em um evento epidemiológico de grande significado, sobretudo pelo grande potencial de disseminação do vírus a partir de animais PI. Por outro lado, a presença de anticorpos no sangue de fetos geralmente indica que a infecção fetal foi seguida da indução de imunidade com a consequente eliminação da infecção (Baker 1995).

Cinco amostras foram isoladas de animais clinicamente saudios, oriundos de rebanhos com histórico de problemas reprodutivos nos Estados de São Paulo e Rio Grande do Sul. Não obstante a denominação originalmente dada ao agente, o BVDV é um vírus essencialmente associado a problemas reprodutivos (Donis 1989, Baker 1995, Moennig \& Liess 1995). Infecções de fêmeas soronegativas podem resultar em uma grande variedade de manifestações que incluem infertilidade com repetição de serviços, mortalidade embrionária precoce ou tardia, abortos, mumificação fetal, malformações fetais, natimortos e o nascimento de bezerros fracos e inviáveis (Baker 1995, Moennig \& Liess 1995). Rebanhos com problemas reprodutivos devidos ao BVDV geralmente possuem um ou mais animais PI, que servem de reservatórios do vírus e fontes de infecção (Baker 1995, Houe 1995). A identificação e eliminação desses animais constitui-se em um requisito fundamental para a erradicação do vírus do rebanho (Donis 1989, Bitsch \& Ronsholt 1995, Houe 1995).

Os casos clínicos dos quais foram isoladas duas amostras do vírus (SV-260/97, LV85/96) ocorreram em animais jovens, que apresentavam quadros de gastrenterite cursando com diarréia, às vezes escura e sanguinolenta e apresentavam ulcerações e erosões no trato digestivo. Em um desses casos (SV260/97), não se soube do envolvimento de outros animais do respectivo rebanho. Tratava-se aparentemente de um caso isolado de enfermidade entérica, que culminou com a morte do animal. Enfermidade gastrentérica com diarréia e erosões na mucosa digestiva constituem-se em manifestações clínicas tipicamente associadas à infecção pelo BVDV (Bolin 1990, Baker 1995). Não obstante, a ocorrência de enfermidade clínica não é uma constante na infecção pelo BVDV (Donis 1989, Baker 1995). A alta prevalência de anticorpos em rebanhos sem histórico clínico indica que a infecção cursa, na maioria das vezes, de forma subclínica ou inaparente (Donis 1989, Baker 1995). Na propriedade de origem 
da amostra LV 85/96 foram relatados abortos recentes e o nascimento de um bezerro com quadro clínico semelhante.

As manifestações clínicas e os achados histopatológicos dos casos de origem dessas amostras assemelhavam-se à Doença das Mucosas, que é uma enfermidade de ocorrência esporádica associada ao BVDV, e que tem uma etiopatogenia peculiar (Brownlie 1990, 1991, Bolin 1990). Em casos de Doença das Mucosas, no entanto, geralmente estão presentes concomitantemente vírus citopáticos e não-citopáticos (McClurkin et al. 1985, Brownlie 1991). A falha em demonstrar atividade citopática no material proveniente dos animais doentes sugere que esses casos representavam quadros de Diarréia Viral Bovina (BVD). Alternativamente, é possível que em algum desses casos tratava-se realmente de Doença das Mucosas, mas que apenas não se conseguiu isolar o vírus citopático do material submetido. Embora possam cursar com manifestações clínicas muito semelhantes e sejam causadas pelo mesmo agente, essas duas formas clínicas possuem etiopatogenias distintas (Bolin 1990, Brownlie 1990, 1991).

Recentemente, amostras altamente virulentas do BVDV associadas a quadros agudos de enfermidade entérica e hemorrágica têm sido descritas nos Estados Unidos e Canadá (Corapi et al. 1989, Pellerin et al. 1994). Essas amostras são genética e antigenicamente diferentes das cepas clássicas e foram provisoriamente classificadas como BVDV tipo II (Pellerin et al. 1994, Ridpath et al. 1994). Apesar de amostras de BVDV do tipo II ainda não tenham sido inequivocamente identificadas fora da América do Norte, seria pertinente tipificar as amostras isoladas desses casos clínicos, por tratar-se de enfermidades clinicamente compatíveis com as descrições de enfermidades associadas a esses vírus.

A grande maioria das amostras isoladas pertence ao biotipo ncp. Esses achados refletem em parte o que ocorre no campo: a grande maioria das amostras de BVDV circulantes na população bovina não produz citopatologia em cultivo celular (Lee \& Gillespie 1957, Liess 1996). A replicação dessas amostras não produz alterações evidentes na morfologia ou na capacidade de crescimento das células de cultivo (Lee \& Gillespie 1957). Por isso, infeç̧ões/contaminações de linhagens celulares com amostras ncp do BVDV podem cursar despercebidas se técnicas de detecção de antígeno não forem utilizadas (Bolin et al. 1994). A ausência de citopatologia pode inclusive eventualmente mascarar e frustrar tentativas diagnósticas de isolamento de vírus em cultivo celular, quando baseadas exclusivamente no aparecimento (ou não) de efeito citopático. Por isso faz-se necessário enfatizar que a grande maioria das amostras de campo do BVDV não produz citopatologia. Consequentemente, a detecção e identificação do vírus em cultivo celular deve obrigatoriamente incluir técnicas de detecção de antígeno, como a imunofluorescência e/ou imunoperoxidase (Potts et al. 1989, Bolin et al. 1994).

Amostras cp são relativamente infrequentes e são isoladas principalmente, embora não exclusivamente, de casos de Doença das Mucosas (Gillespie et al. 1960, Vidor 1974, McClurkin et al. 1985, Ridpath et al. 1991). Por isso o percentual de amostras cp em relação ao total de amostras isoladas no presente estudo é ainda relativamente alto. Este alto índice pode ser explicado pelo fato de que durante muitos anos a detecção de BVDV em amostras clínicas baseava-se exclusivamente no aparecimento de efeito citopático. Com isso, provavelmente nesse período ocorreram isolamentos preferencialmente de amostras cp, em detrimento de amostras ncp, que possivelmente passaram despercebidas. Ou seja, o índice de amostras cp em relação ao total, ainda é excessivamente alto se comparado aos índices usualmente observados entre amostras de campo, nos quais as amostras ncp representam a grande maioria (Liess 1996).

A maioria dos vírus cp origina-se de amostras ncp, através de mutações ou recombinações no genoma (Brownlie 1990, Meyers et al. 1991, 1992, 1996). Devido a isso, em amostras que produzem citopatologia, é comum a presença de vírus dos dois biotipos (McClurkin et al. 1985, Ridpath et al. 1991, Liess 1996). O evento molecular central que caracteriza as amostras cp é a produção do polipeptídeo NS3/p80 (Donis \& Dubovi 1987). A produção desse polipeptídeo pode ocorrer através da clivagem da proteína não estrutural NS23/p125 ou por duplicação do gene que codifica a NS3/p80 (Meyers et al. 1996). Amostras que não produzem a NS3/p80 são geralmente não-citopáticas em cultivo celular (Donis 1995, Meyers et al. 1996). A análise das proteínas virais das amostras analisadas por "Western-immunoblot" demonstrou uma perfeita correlação entre a expressão da NS3/ p80 e a indução de citopatologia em cultivo celular. Em uma das amostras (IBSP-4), evidenciou-se a produção da proteína NS3/ p80 (Fig. 3B, linha 5) antes da produção de citopatologia. Não se determinou o mecanismo de geração da NS3/p80 por esses vírus no presente estudo, constituindo-se em objeto para futuras investigações.

A caracterização dos isolados com um painel de AcMs revelou a existência de uma diversidade antigênica marcante entre as amostras locais do BVDV. A grande variabilidade antigênica é uma característica universal dos Pestivirus em geral (Edwards \& Paton 1995) e do BVDV em particular (Dubovi 1992). Apesar da diversidade antigênica marcante, ainda não foi possível o estabelecimento definitivo de sorotipos (Dubovi 1992, Edwards \& Paton 1995). A maior variabilidade observada na glicoproteína E2/gp53 é explicável pelo fato da E2/gp53 ser a glicoproteína mais abundante do envelope do vírus e ter papel predominante nos estágios iniciais da infecção celular (Donis 1995). Com isso, é o principal alvo para anticorpos neutralizantes e está submetida à intensa pressão de seleção, resultando em mutações constantes e seleção de variantes antigenicamente diferentes (Donis et al. 1988, Corapi et al. 1990, Donis 1995). AcMs que reconhecem determinantes antigênicos variáveis são úteis para a caracterização e diferenciação de isolados, enquanto AcMs com amplo espectro de reatividade (como o 20.10.6 e 15c5) têm grande utilidade para o diagnóstico, pois reagem com a grande maioria das amostras de campo (Corapi et al. 1990, Edwards \& Paton, 1995).

A grande variabilidade antigênica do BVDV, sobretudo na glicoproteína E2/gp53, pode ter importantes implicações para o diagnóstico e para estratégias de imunização. Nesse sentido, a utilização rotineira das cepas citopáticas norte-americanas Singer, NADL e Oregon em testes de soro-neutralização deve ser reavaliada. Essas cepas são antigenicamente distintas das amos- 
tras brasileiras (Quadro 2) e podem estar falhando em detectar níveis baixos de anticorpos contra amostras antigenicamente diferentes. Da mesma forma, as vacinas contra o BVDV disponíveis no mercado brasileiro contêm apenas cepas norte-americanas ou européias. Devido a variabilidade antigênica observada entre as amostras brasileiras, sobretudo em relação às cepas norte-americanas, é pertinente questionar o grau de proteção induzida por essas vacinas contra as amostras brasileiras do vírus.

Em resumo, o presente artigo apresenta um perfil preliminar de amostras de BVDV isoladas no Brasil até o momento. Um conhecimento mais abrangente e detalhado sobre os vírus que circulam no rebanho bovino do país, no entanto, requer o isolamento e a caracterização de um número maior de amostras. Esforços nesse sentido estão sendo realizados e constituem-se em prioridades dos laboratórios envolvidos no presente estudo.

Agradecimentos.- Ao Dr. Ruben Donis, University of Nebraska/Lincoln, pelos anticorpos monoclonais e cepas-padrão do BVDV; ao Frigorífico Silva, Santa Maria, RS e a Empresa Kienast \& Kratschmer S.A, Portão, RS, pelo envio de amostras de soro de fetos bovinos para isolamento de vírus; ao Prof. Dr. David Driemeier (Faculdade de Veterinária, UFRGS) e Prof. Dr. Célso Pilati (UDESC, Lages, SC) pelos trabalhos de necropsia e patologia nos casos clínicos LV85/96 e SV-260, respectivamente. Durante a execução do trabalho, S.A.B era bolsista de mestrado da CAPES. L.H.V.G.G. possui bolsa de mestrado do CNPq. Este estudo foi executado com recursos do MCT, CNPq, CAPES, e FINEP (PRONEX em Virologia Veterinária, Proc. $\left.n^{\circ} 215 / 96\right)$.

\section{REFERÊNCIAS}

Ausubel F.M., Brent R., Kingston R.E., Moore D.D., Seidmann J.G., Smith J.A. \& Struhl K. 1989. Analysis and manipulation of proteins, p.10.1.110.8.16. In: Current Protocols in Molecular Biology, vol. 1. Willey, New York.

Baker J.C.1995. The clinical manifestations of bovine viral diarrhea infections. Vet. Clin. North America 11:427-444.

Bitsch V. \& Ronsholt L.1995. Control of bovine viral diarrrhea virus without application of vaccines. Vet. Clin. North America 11:627-640.

Bolin S.R. 1990. The current understanding about the pathogenesis and clinical forms of BVD. Vet. Med. 85:1123-1132.

Bolin S.R., Ridpath J.F. \& Black J. 1994. Survey of cell lines in the American Type Culture Collection for bovine viral diarrhea virus. J. Virol. Methods 48:211-219.

Brownlie J. 1990. Pathogenesis of mucosal disease and molecular aspects of bovine viral diarrhea virus. Vet. Microbiol. 23:371-379.

Brownlie J. 1991. The pathways for bovine viral diarrhea virus biotypes in the pathogenesis of disease. Arch. Virol. 3 (Suppl.):79-86.

Corapi W.V., French T.W. \& Dubovi E.J. 1989. Severe thrombocytopenia in young calves experimentally infected with noncytopathic bovine viral diarrhea virus. J. Virol. 62:2823-2827.

Corapi W.V., Donis R.O. \& Dubovi E.J. 1990. Characterization of a panel of monoclonal antibodies and their use in the study of the antigenic diversity of bovine viral diarrhea virus. Am. J. Vet. Res. 51:1388-1394.

Correa W.M., Netto Z.C. \& Barros H.M. 1968. Nota clínico-patológica de uma enfermidade das mucosas em São Paulo. Arq. Inst. Biológico, São Paulo, 35:141-151.

Correa W.M., Gottschalk A.F. \& Correa C. 1972. Observações na diarréia a vírus dos bovinos no Estado de São Paulo. Arq. Inst. Biológico, São Paulo, 38:145-147.

Donis R. \& Dubovi E.J. 1987. Differences in virus-induced polypeptides in cells infected by cytopathic and noncytopathic biotypes of bovine virus diarrhea-mucosal disease virus. Virology 158:168-173.

Donis R.O., Corapi W. \& Dubovi E.J. 1988. Neutralizing monoclonal antibodies to bovine viral diarrhea virus bind to the $56 \mathrm{~K}$ to $58 \mathrm{~K}$ glycoprotein. J. Gen. Virol. 69:77-86.

Donis R. 1989. Bovine viral diarrhea: the unraveling of a complex of clinical presentations. Bovine Proceedings 20:16-22.

Donis R. 1995. Molecular biology of bovine viral diarrhea virus and its interactions with the host. Vet. Clin. North America 11:393-421.

Dubovi E.J. 1992. Genetic diversity and BVD virus. Comp. Immunol. Microbiol. Infect. Dis. 15:155-162.

Edwards S. \& Paton D. 1995. Antigenic differences among pestiviruses. Vet. Clin. North America 11:563-578.

Francki R.I.B., Fauquet C.M., Knudson D.L. \& Brown F. 1991. Classification and nomenclature of viruses. Fifth Report of the International Committee on the Taxonomy of viruses. Arch. Virol. 2 (Suppl.):228-229.

Gillespie J.H., Baker J.A. \& McEntee K. 1960. A cytopathogenic strain of virus diarrhea virus. Cornell Vet. 50:73-79.

Houe H. 1995. Epidemiology of bovine viral diarrhea virus. Vet. Clin. North America 11:521548.

Laemnli U.K. 1970. Cleavage of strutural proteins during the assembly of the head of bacteriophage T4. Nature (London) 227:680-685.

Lee K.M. \& Gillespie J.H. 1957. Propagation of virus diarrhea virus of cattle in tissue culture. Am. J. Vet. Res. 18:952-955.

Liess B. 1996. Cytopathogenicity discovery and impact in BVD research. p. 11-15. Proc. Int. Symp. Bovine Viral Diarrhea Virus - a 50 year review. June, 23-25. Cornell, NY.

Mayr A. \& Guerreiro M.G. 1981. Virologia Veterinária. Sulina. 2a ed. Porto Alegre, RS. 472p.

McClurkin A.W., Bolin S.R. \& Coria M.F. 1985. Isolation of cytopathic and noncytopathic bovine viral diarrhea virus from the spleen of cattle acutely and chronically affected with bovine viral diarrhea. J. Am. Vet. Med. Assoc. 186:568-575.

Meyers G., Tautz N. \& Dubovi E.J. 1991. Viral cytopathogenicity correlated with integration of ubiquitin-coding sequences. Virology 180:602-610.

Meyers G., Tautz N. \& Stark R. 1992. Rearrangement of viral sequences in cytopathogenic pestiviruses. Virology, 191:368-376.

Meyers G., Tautz N., Dubovi E. \& Thiel H-J. 1996. Origin and diversity of cytopathogenic pestiviruses. p. 24-34. Proc. Int. Symp. Bovine Viral Diarrhea Virus - a 50 year review. June, 23-25. Cornell, NY.

Moennig V. \& Liess B. 1995. Pathogenesis of intrauterine infections with bovine viral diarrhea virus. Vet. Clin. North America 11:477-487.

Oliveira L.G., Oliveira E.A.S., Silva L.H.T., Vieira L.A., Hoffmann V.L., Fernandes G.V., Silva T.C., Caldas A.P.F. \& Roehe P.M. 1996. Presença de pestivírus e anticorpos contra pestivírus em soros e cultivos celulares. Arq. Bras. Med. Vet. Zoot. 48:513-521.

Pellerin C., van den Hurk J. \& Lecomte, J. 1994. Identification of a new group of bovine viral diarrhea virus strains associated with severe outbreaks and high mortalities. Virology 203:260-267.

Potts B.J., Sawyer M., Shekarchi I.C., Wismer T. \& Huddleson D.1989. Peroxidase-labelled primary antibody method for detection of pestivírus contamination in cell cultures. J.Virol. Methods 26:119-124.

Ridpath J.F., Lewis T.L. \& Bolin S.R. 1991. Antigenic and genomic comparison between non-cytopathic and cytopathic bovine viral diarrhoea viruses isolated from cattle that had spontaneous mucosal disease. J. Gen. Virol. 72:725-732.

Ridpath J., Bolin S. \& Dubovi E. 1994. Segregation of Bovine Viral Diarrhea Virus into genotypes. Virology 205:66-74.

Roehe P.M., Oliveira E.A.S., \& Oliveira L.G. 1995. Characterization of field and cell culture isolates of bovine viral diarrhea virus (BVDV) with monoclonal antibodies. Virológica, Ribeirão Preto, SP, B-6.

Soares L.A. \& Carvalho Pereira D.A. 1974. Neutralizing antibodies against bovine viral diarrhea virus-mucosal disease virus in cattle sera from, São Paulo, Brazil. Revta Microbiol. 5:1-5.

Vidor T. 1974. Isolamento e identificação do vírus da doença das mucosas no Rio Grande do Sul. Bolm Inst. Pesq. Vet. Des. Finamor, Porto Alegre, 5:51-58. 